УДК 536.24:532.517.4

C.A. Рева, асп., ORCID 0000-0003-0226-706X

Національний технічний університет України «Київський політехнічний інститут імені Ігоря Сікорського»

\title{
СFD - МОДЕЛЮВАННЯ ТЕЧІЇ ВСЕРЕДИНІ ГВИНТОПОДІБНИХ ТРУБ
}

\begin{abstract}
Представлений аналіз математичних моделей турбулентності для числового моделювання теплообмінних процесів в гвинтоподібних трубах. Запропонована методика числового дослідження теплообміну всередині труб з рівнорозвиненою поверхнею, які виготовлені за технологією, щзо розроблена в КПІ ім. Ігоря Сікорського. Проведена валідація даної методики для двох типорозмірів гвинтоподібних труб. Виконані числові дослідження впливу геометричних характеристик та кількості заходів гвинтової канавки на процеси теплообміну в діапазоні чисел Рейнольдса від 15000 до 65000. Аналіз отриманих результатів свідчить, щуо гвинтоподібні труби мають в 1,5-2,6 рази вищу інтенсивність тепловіддачі в порівнянні з гладкими трубами. Вперше визначено вплив кількості заходів гвинтової канавки на інтенсивність теплообміну всередині труби. Результати дослідження можуть бути використані при розробиі теплообмінників типу «газ-газ».

Ключові слова: гвинтоподібна труба, рівнорозвинена поверхня, теплообмін, ефективність, інтенсифікація, вимушена конвекція, числове моделювання

Вступ

Одним з методів підвищення ефективності газотурбінних установок (ГТУ) є застосування систем регенерації теплоти викидних газів. При цьому задача забезпечення максимально можливого ступеню регенерації пов'язана зі зменшенням температурних напорів. Тому при використанні теплообмінників в яких теплообмінна поверхня складається з гладких круглих труб виникає проблема з значним збільшенням габаритів, маси та втрат тисків в газоповітряному тракті установки.

Вирішення цих проблем досягається шляхом застосування теплообмінних поверхонь у вигляді гвинтоподібних труб, що мають одночасний значний ступінь розвинення, як внутрішньої, так і зовнішньої поверхонь труби. Такі труби були розроблені та досліджуються спеціалістами КПІ ім. Ігоря Сікорського для теплообмінників типу "газ - газ” [1,2].
\end{abstract}

\section{Мета та завдання}

Робота пов'язана 3 розробкою методики числового моделювання процесів теплообміну при вимушеній течії теплоносія всередині гвинтоподібних трубах, проведення числових досліджень та аналізу отриманих даних.

\section{Вибір математичної моделі}

Як правило, в регенераторах ГТУ реалізується турбулентний режим течії теплоносія. Такий режим $\epsilon$ складним для математичного опису, оскільки турбулентні пульсації істотно впливають на перенесення імпульсу тепла та маси, що в свою чергу впливає на розподіл швидкостей, температури по потоку. Тому їх безпосередній розрахунок за допомогою диференційних рівнянь переносу імпульсу теплоти і маси, без застосування моделей турбулентності неможливий навіть при використанні суперкомп'ютерів $[3,4]$.

В даному розділі статті розглядається проблема з вибору математичної моделі для комп’ютерного моделювання процесів теплообміну складних закручених течій в гвинтоподібній трубі, що має один чи більше заходів гвинтової канавки.

Математична модель для розрахунку таких течій складається з осереднених по Рейнольдсу рівнянь Нав’є - Стокса, енергії та рівнянь, що встановлюють зв'язок тензора турбулентних напружень 3 тензором осереднених швидкостей деформації (моделей турбулентності).

Оскільки не існує універсальної моделі для всіх типів інженерних задач, зараз в літературних джерелах представлена велика кількість моделей турбулентності - одно-, дво- та багатопараметричних.

До однопараметричних моделей відносять найпростішу модель Спаларта - Алмареса[5], що складається з системи основних рівнянь та одного додаткового диференційного рівняння. Згідно [6-8] ця модель дає гарні результати для пограничних шарів, що характеризуються додатними градієнтами тиску та ефективно працює для режимів з малими числами Рейнольдса, але не має застосовуватись при розрахунку відривних течій. 


\section{ISSN 1813-5420 (Print). Енергетика: економіка, технологіï, екологія. 2017. № 4}

До двопараметричних відносять сімейство моделей турбулентності на основі відомої $\mathrm{k}-\varepsilon$ моделі, що була описана в статті Лаундера Джонса в 1972 році [9], в якій турбулентна в'язкість визначається 3 додаткових диференційних рівнянь, що описують процеси переносу кінетичної енергії турбулентних пульсацій $\mathrm{k}$ та зміну швидкості дисипації турбулентної енергії $\varepsilon$.

На думку автора [10] головна причина недостатньої універсальності двопараметричних моделей турбулентності до розрахунку криволінійних та закручених потоків полягає в припущенні, що турбулентність $є$ ізотропною.

В багатопараметричних моделях турбулентності безпосередньо визначаються 3 диференційних рівнянь напруження Рейнольдса. Це дозволяє істотно краще враховувати попередню історію потоку, центробіжні ефекти, кривизну ліній току і т.д. Однак для тривимірної течії необхідно розраховувати шість додаткових рівнянь. Основа таких моделей була закладена в роботах Дж. Роди, П.Я. Чоу, В.І. Давидовим [11-13]. Так як модель не використовує припущення про ізотропність турбулентної в’язкості, то вона $\epsilon$ надійною при вивченні процесів в системах зі складною геометрією, а також в процесах, що ускладнені закрученням потоку.

На основі вище зазначеного робимо висновок, що для числового моделювання процесів теплообміну всередині гвинтоподібних труб є сенс використовувати багатопараметричну модель Рейнольдсових напружень.

\section{Розрахункова область}

В якості розрахункової області береться об’єм труби (рис.1), що обмежений вхідним та вихідним перетинами та внутрішньою стінкою труби, яка $\epsilon$ непроникною. Поверхня труби утворюється поворотом профілю витка та просуванням його вздовж гвинтової лінії - спіраль з кроком $\mathrm{t}$ та діаметром $\mathrm{d}_{\text {вн. }}$.

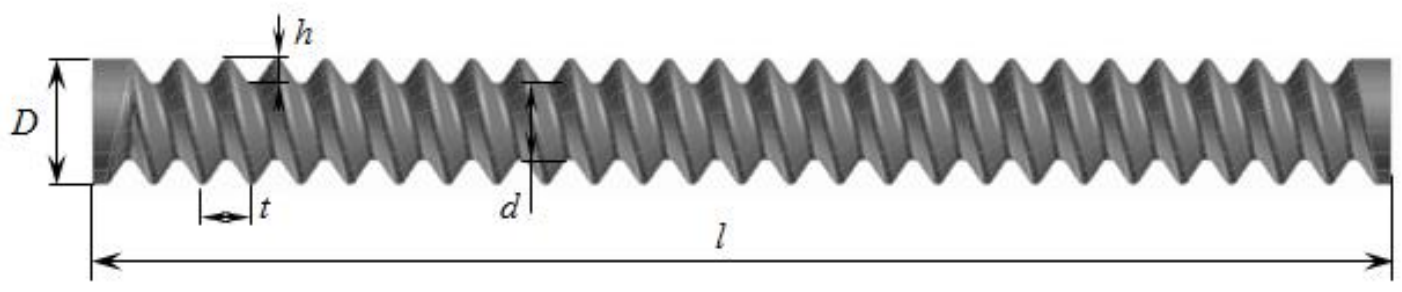

Рисунок 1 - Модель гвинтоподібної труби

Досліджено три типорозміри труб (рис. 2), що відрізнялись геометричними характеристиками профілю витка, та відрізнялись кількістю заходів гвинтової канавки (рис.3). Основні величини геометричних параметрів дослідних моделей труб представлені в табл. 1.

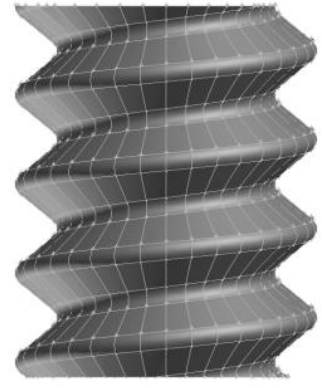

a)

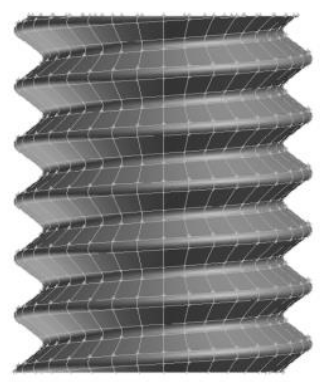

б)

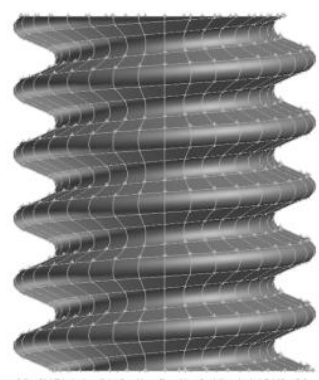

в)

а) 1 ; б) 2 в) 3

Рисунок 2. - Типорозміри моделей гвинтоподібних труб 
ISSN 1813-5420 (Print). Енергетика: економіка, технології, екологія. 2017. № 4

Таблиця 1 - Геометричні параметри моделей гвинтоподібних труб

\begin{tabular}{|c|c|c|c|c|c|c|c|c|c|}
\hline $\begin{array}{c}\text { № } \\
\text { труби }\end{array}$ & Типорозмір & $\begin{array}{c}\text { l } \\
\text { мM }\end{array}$ & $\begin{array}{c}D \\
\text { мм }\end{array}$ & $\begin{array}{c}d \\
\text { мM }\end{array}$ & $\begin{array}{c}t \\
\text { MM }\end{array}$ & $\begin{array}{c}h \\
\text { мм }\end{array}$ & $t / h$ & $\psi$ & $\mathrm{Z}^{* *}$ \\
\hline $1 *$ & 1 & \multirow{7}{*}{320} & \multirow{7}{*}{36} & 26 & 12 & 5 & 2,4 & 1,163 & 1 \\
\hline $2 *$ & \multirow{4}{*}{2} & & & \multirow{4}{*}{30} & \multirow{4}{*}{8} & \multirow{4}{*}{3,5} & \multirow{4}{*}{2,28} & \multirow{4}{*}{1,241} & 1 \\
\hline 3 & & & & & & & & & 2 \\
\hline 4 & & & & & & & & & 3 \\
\hline 5 & & & & & & & & & 4 \\
\hline 6 & \multirow{2}{*}{3} & & & \multirow{2}{*}{26} & \multirow{2}{*}{9} & \multirow{2}{*}{5} & \multirow{2}{*}{1,8} & \multirow{2}{*}{1,372} & 1 \\
\hline 7 & & & & & & & & & 4 \\
\hline
\end{tabular}

* - для гвинтоподібних труб № 1,2 проведені експериментальні дослідження теплообміну

** - кількість заходів гвинтової канавки


a)

б)

B)

г)

а), б), в), г) - одно-, дво-, трьох-, чотирьохзахідна гвинтоподібна труба відповідно

Рисунок 3 - Моделі труб 2 типорозміру з різною кількістю заходів гвинтової канавки. Вид з боку та живий перетин.

Дискретизація розрахункових моделей гвинтоподібних труб

Дискретизація розрахункової області впливає на точність розрахунку вимушеної течії всередині гвинтоподібної труби за допомогою вибраної математичної моделі. 


\section{ISSN 1813-5420 (Print). Енергетика: економіка, технології, екологія. 2017. № 4}

Від параметру $\mathrm{y}^{+}$залежить точність розрахунку першого шару чарунок біля стінки обраною математичною моделлю, який впливає на розрахунок всієї області. Тому розбивка геометричної моделі на розрахункову сітку повинна бути такою, щоб $\mathrm{y}^{+} \leq 1$.

При дискретизації розрахункової області застосовували такі умови:

- сітка була нерівномірна, зі згущенням до поверхні труби (рис.4);

- товщина першого шару дорівнювала $10^{-5}$ м, вибиралась згідно рекомендації [14];

- товщина кожного 319 наступних шарів була на $10 \%$ більшою ніж попереднього;

- товщина кожного $з$ наступних N-шарів була на 20\% більшою ніж попереднього N-1 шару;

- розмір чарунки в поздовжньому напрямку теж змінювався від 0,5 до 3 мм на осі гвинтоподібної труби.

Завдяки такому підходу значення параметра $\mathrm{y}^{+}$було в межах від 0,3 до 0,5 .

Кількість чарунок для дискретизації геометричних моделей, що досліджуються, склала від 8,8 до 14 млн..
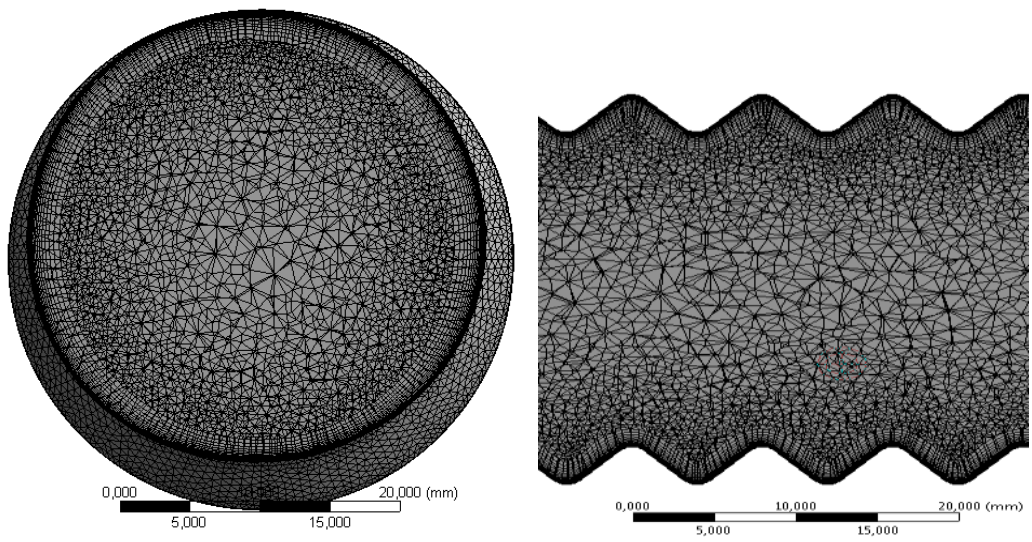

Рисунок 4. - Розрахункова сітка

\section{Граничні умови}

На межах розрахункової області задавались такі граничні умови:

- вхідний перетин: температура повітря $T^{\prime}=293 \mathrm{~K}$; тиск повітря на вході $P^{\prime}=P_{\text {атм }}$;

- на стінці труби задавались граничні умови $T_{\text {ст }}=$ const

- вихідний перетин: витрата теплоносія $G=i d e m$.

\section{Валідація методики числового моделювання}

Проведено порівняння даних, що отримані за допомогою методики числового моделювання та даних, що отримані експериментально для поверхонь №1,2 [15] (рис. 5). Відхилення лежать в межах $\pm 5 \%$.

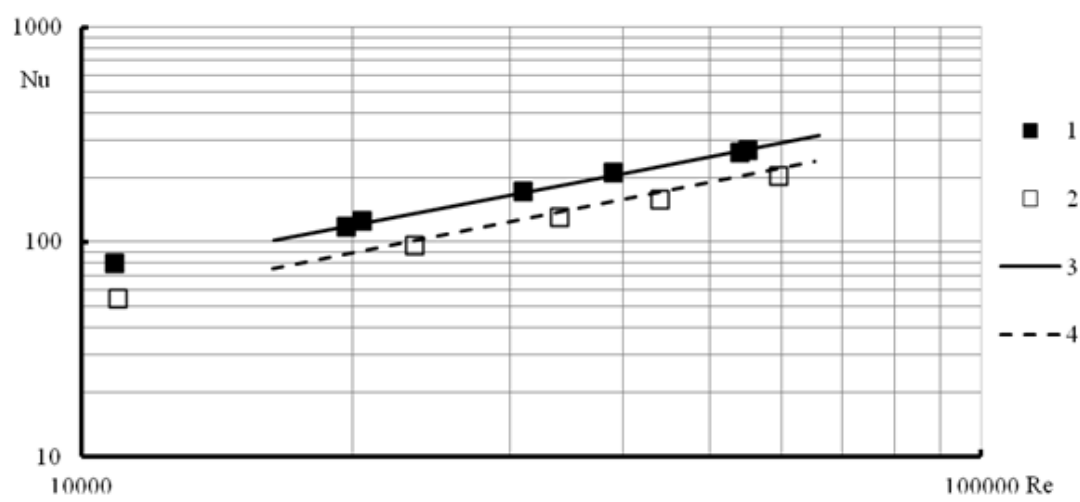

1, 2 - гвинтоподібна труба №1,2 відповідно - дослідні дані;

3,4 - гвинтоподібна труба №1,2 відповідно результати числового моделювання

Рисунок 5. - Залежність чисел Нуссельта від чисел Рейнольдса 


\section{Результати досліджень}

Дослідження конвективного середньоповерхового теплообміну гвинтоподібних труб виконані в діапазоні зміни чисел Рейнольдса $\mathrm{Re}=15000$ - 65000. На рисунку 6 в логарифмічних координатах $\mathrm{Nu}-\mathrm{Re}$ наведені дослідні дані та дані, що розраховані за методикою [16], для гладкої труби.

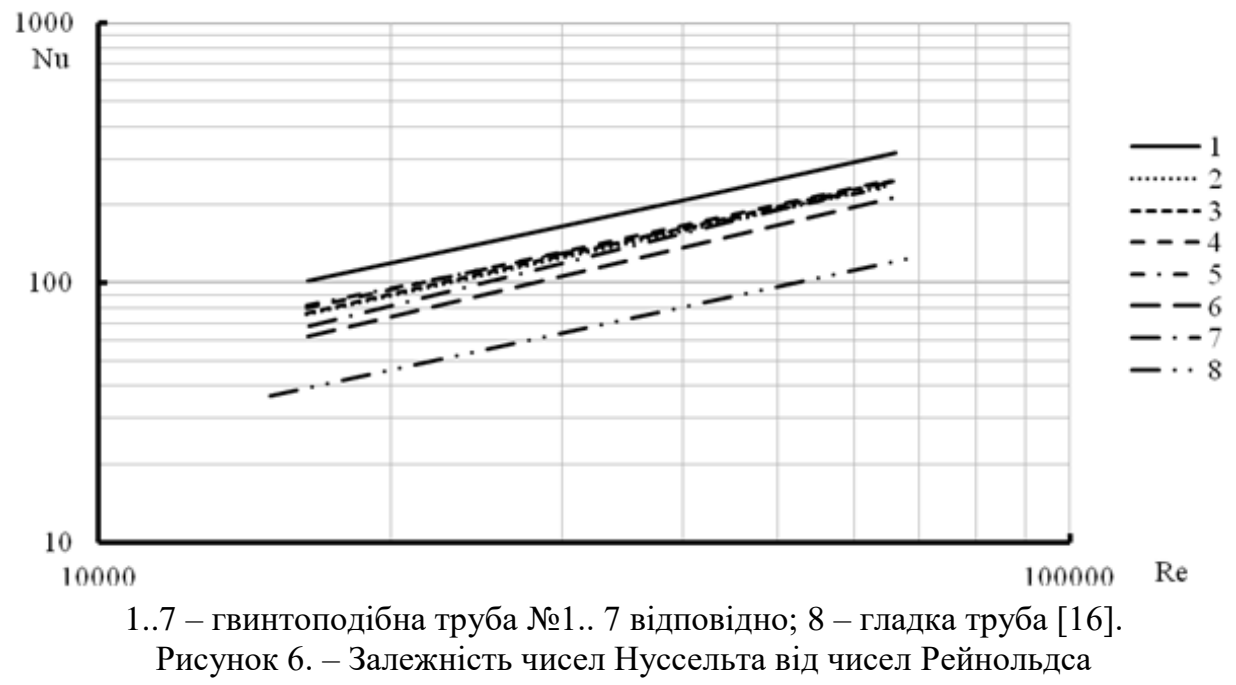

Аналіз отриманих результатів показав, що інтенсивність тепловіддачі для гвинтоподібних труб в 1,5 - 2,6 рази вище ніж для гладкої труби. При цьому максимальний рівень інтенсифікації характерний для гвинтоподібної труби $3 \mathrm{t} / \mathrm{h}=2,4$ та одним заходом гвинтоподібної канавки. Такий ефект, як показали числові дослідження, можна пояснити складним рухом теплоносія, що супроводжується утворенням інтенсивних вторинних вихрових структур. В результаті, рівень збуреності потоку значно зростає.

При порівнянні результатів дослідження 3 теплообміну для гвинтоподібних труб виявлено, що найбільш явним фактором, який впливає на інтенсивність теплообміну, $є$ відносний крок гвинтової канавки $t / h$. При збільшені величини $t / h$ від 1,8 до 2,4 зростає інтенсивність теплообміну всередині гвинтоподібних труб на 48 - 66 \% в залежності від режиму течії.

Аналізуючи вплив кількості заходів гвинтової канавки на інтенсивність теплообміну, отримано, що для гвинтоподібної труби з геометричними характеристиками канавки $t=9$ мм та $h=5$ мм при збільшені заходів гвинтової канавки від 1 до 4 в залежності від режиму течії спостерігається приріст тепловіддачі від 9 до $16 \%$. Однак для гвинтоподібної труби з $t=8$ мм та $h=3,5$ мм отримано ефект збільшення інтенсивності тепловіддачі до 8\% при збільшені кількості заходів гвинтової канавки від 1 до 4 тільки для низьких чисел Рейнольдса. Цей ефект можна пояснити зниженням рівня обуреності потоку. При одночасному збільшені кількості заходів гвинтової канавки та числа Рейнольдса показник степеня в залежності $\mathrm{Nu}=C q \cdot \mathrm{Re}^{m}$ знижується від 0,84 до 0,77 .

Зіставлення отриманих результатів з теплообміну для гвинтоподібних труб, що мають однакову глибину канавки $h=5$ мм, показало вплив кроку між сусідніми канавками на теплообміні процеси всередині таких труб. При збільшені кроку з $t=9$ мм до $t=12$ мм зростає інтенсивність теплообміну на 47 $-66 \%$.

\section{Висновки}

Інтенсивність тепловіддачі всередині гвинтоподібних труб в 1,6-2,6 рази вище ніж для вихідної гладкої труби. Максимальний рівень інтенсифікації характерний для гвинтоподібної труби 3 відносним кроком гвинтової канавки $t / h=2,4$.

В подальших дослідженнях гвинтоподібних труб з рівнорозвиненою поверхнею передбачається провести аналіз їх теплоаеродимічної ефективності, оскільки коефіцієнт теплопередачі помітно посилюється ефектом одночасного розвинення внутрішньої та зовнішньої поверхонь труб, яке досягає від $16 \%$ до 37\%, що відкриває гарні перспективи.

\section{Список використаної літератури}

1. Письменный Е. Н., Баранюк А.В., Вознюк М.М. Равноразвитые поверхности теплообмена и методика численных исследований их теплогидравлических характеристик . Промышленная теплотехника. 2012. Т.34, №1. С.45-54.

2. Теплообмінна труба: пат. 67783 Україна. МПК F28F 1/08, F28F 1/42, F28F 13/02. №u201108293. 


\section{ISSN 1813-5420 (Print). Енергетика: економіка, технології, екологія. 2017. № 4}

заявл. 01.07.2011; опубл. 25.07.2012, Бюл. №5. 5c.

3.Бубенчиков А.М., Харламов С.Н. Математические модели неоднородной анизотропной турбулентности во внутренних течениях. Томск.: Томский государственный университет, 2001. 448 с.

4.Харламов С.Н. Алгоритмы при моделировании гидродинамических процессов. Томск.: Изд-во ТПУ, 2008. 80c.

5. Spalart P.R., Allmares S.R. A one - equation turbulence model for aerodynamic flows. La Recherche Aerospatiale. 1994. No1. P.5-21.

6.Субботина П.Н., Шишаева А.С. Применение различных моделей турбулентности для задач внешнего обтекания в программном комплексе FLOWVISION

URL:http://tesis.com.ru/infocenter/downloads/flowvision/fv_es08_turbul.pdf. (Дата звернення 10.12.2017)

7. Габарук А.В., Стрелец М.Х., Шур М.Л. Моделирование турбулентности в расчетах сложных течений: учебное пособие. СПб.: Изд-во Политехн. ун-та, 2012. 88c.

8. Габарук А.В.Современные подходы к моделированию турбулентности: учебное пособие. СПб.: Изд-во Политехн. ун-та, 2016. 234c.

9. Jones W.P., Launder B.E. The prediction of laminarization with a two-equation model of turbulence. International Journal of Heat and Hass Transfer. 1972. Vol.15, No2. P. 301-314.

10. Митрофанова О.В. Гидродинамика и теплообмен закрученных потоков в каналах ядерно энергетических установок. М.: ФИЗМАТЛИТ, 2010. 288c.

11.Rotta J.C. Statistiche theorie nichthomogener turbulenz. Zeitschrift fur physik. 1951. Vol.129, No5. P.547-572.

12. Chou P.Y. One the velocity correlations and the solution of the equations of turbulent fluctuations. Quarterly Journal of Applied Mathematics. 1945. Vol.3, P.31-38.

13. Давыдов Б.И. К статистической динамике несжимаемой турбулентной жидкости. Доклады академии наук. 1961. Т.136, №1. С.47-50.

14. Быстров Ю.А., Исаев С.А., Кудрявцев Н.А., Леонтьев А.И. Численное моделирование вихревой интенсификации теплообмена в пакетах труб. СПб.: Судостроение, 2005. 389 с.

15. Демчук Л.В., Рогачов В.А., Терех О.М., О.І.Руденко. Теплоаеродинамічна ефективність гвинтоподібних труб 3 рівнорозвиненою поверхнею. Восточно-Европейский журнал передовых технологий. 2007. Т53, №5/8. С. 26-30.

16.Тепловой расчет котельных агрегатов: нормативный метод /под ред. Н.В. Кузнецова. М.: Энергия, 1973. 296 с.

\section{S. Reva, Ph. D. student., ORCID 0000-0003-0226-706X National Technical University of Ukraine "Igor Sikorsky Kyiv Polytechnic Institute" CFD - SIMULATION OF STREAM IN HELICAL GROOVED TUBES}

Analysis of mathematical models of turbulence for numerical simulation of process of heat exchange in helical grooved tubes is presented. The technique of a numerical research of heat exchange in tubes with a equally developed surfaces made behind technology which is developed in Igor Sikorsky KPI is offered. Validation of this technique for two standard sizes of helical tubes is carried out. Numerical researches of influence of geometrical characteristics and the number of starts of a screw groove on processes of heat exchange within the range of Reynolds numbers from 15000 to 65000. The analysis of numerical data demonstrates that helical tubes have 1,5 - 2,6 times above intensity of heat exchange in comparison with smooth tubes. Influence of number of starts of a screw groove on intensity of heat exchange in a tube is for the first time defined. Results of the research can be used in the development of gas-to-gas heat exchangers.

Keywords: helical tube, equaldeveloped surface, heat transfer, efficiency, intensification, forced convection, numerical simulation.

\section{References}

1. E.N. Pis'mennyi, O.V. Baraniuk, M.M. Vozniuk, "Equal developed surfaces of heat exchange and method of numerical researches them heat hydraulic of descriptions," Industrial heat engineering,vol.34, no1, pp. 45-54, 2012

2. E.N. Pis'mennyi et al., "Teploobminna truba [Heat exchange tubes]," UA Patent 67783, July 25, 2012.

3. A.M. Bubenchikov, S.N. Kharlamov, "Matematicheskiye modeli neodnorodnoy anizotropnoy turbulentnosti vo vnutrennikh techeniyakh [ Mathematical models of heterogeneous anisotropic turbulence are in internal flows]," Tomsk: Tomsk State University, 2001. 448p.

4. S.N. Kharlamov, "Algoritmy pri modelirovanii gidrodinamicheskikh protsessov [Algorithms at the design of hydrodynamic processes]," Tomsk: Tomsk Polytechnic University, 2008. 
5. P.R. Spalart, S.R. Allmares, "A one - equation turbulence model for aerodynamic flows," La Recherche Aerospatiale, no1, pp.5-21, 1994.

6. P.N. Subbotina, A.S. Shishayeva, "Primeneniye razlichnykh modeley turbulentnosti dlya zadach vneshnego obtekaniya v programmnom komplekse FLOWVISION [Application of differentmodels of turbulence for the tasks of the external flowingaround in a programmatic complex FFLOWVISION]," [Online]. Available: URL:http://tesis.com.ru/infocenter/downloads/flowvision/fv_es08_turbul.pdf.

7. A.V. Gabaruk, M.Kh. Strelets, M.L. Shur, "Modelirovaniye turbulentnosti v raschetakh slozhnykh techeniy [A design ofturbulence is in the calculations of difficult flows]," St. Petersburg: St.Petersburg Polytechnic University, 2012.

8. A.V. Gabaruk, "Sovremennyye podkhody k modelirovaniyu turbulentnosti [Modern approaches to modeling of turbulence]," St. Petersburg: St.Petersburg Polytechnic University, 2016.

9. W.P. Jones, B.E. Launder, "The prediction of laminarization with a two-equation model of turbulence," International Journal of Heat and Hass Transfer, vol.15, no2, pp. 301-314, 1972.

10. O.V. Mitrofanova, "Gidrodinamika i teploobmen zakruchennykh potokov v kanalakh yaderno - energeticheskikh ustanovok [Hydrodynamics and heat transfer of swirling flows in channels of nuclear power plants]," Moscow:FIZMALIT, 2010. $572,1951$.

11. J.C. Rotta, "Statictiche theorie nichthomogener turbulenz," Zeitschrift fur phusik, vol.129, no5, pp.547-

12. P.Y. Chou, "One the velocity correlations and the solution of the equations of turbulent fluctuations," Quarterly Journal of Applied Mathematics, vol.3, pp.31-38,1945.

13. B.I. Davydov, "K statisticheskoy dinamike neszhimayemoy turbulentnoy zhidkosti [To the statistical dynamics of an incompressible turbulent fluid]," Reports of the Academy of Sciences, vol.136, no1, pp.47-50, 1961.

14. Yu.A. Bystrov, S.A. Isayev, N.A. Kudryavtsev, A.I. Leontyev, "Chislennoye modelirovaniye vikhrevoy intensifikatsii teploobmena $\mathrm{v}$ paketakh trub [A numeral design of vertical intensification of heatexchange is in the packages of pipes ]," St.Petersburg:Sudostroeniye,2005.

15. L. V. Demchuk et al,"Heat - aerodynamic efficiency of helical tubes with equaldeveloped surface", Eastern - European Journal of Enterprise Technologies, vol. 53, no. 5, pp. 26-30, 2011 (in Ukrainian).

16. N.V. Kuznetsova. "Teplovoy raschet kotel'nih agregatov: normativniy metod [Termal calculation of boilers: normative method]," Moscow: Energy, 1973.

\section{УДК 536.24:532.517.4}

Национальный технический университет Украины «Киевский политехнический институт имени Игоря Сикорского» CFD - МОДЕЛИРОВАНИЕ ТЕЧЕНИЯ ВНУТРИ ВИНТООБРАЗНЫХ ТРУБ

Представлен анализ математических моделей турбулентности для численного моделирования теплообменных прочессов в винтообразных трубах. Предложена методика чесленного исследования теплообмена внутри труб с равноразвитой поверхностью изготовленных за технологией которая разработана в КПИ им. Игоря Сикорского. Проведена валидаџия данной методики для двух типорозмеров винтообразных труб. Выполены чесленные исследования влияния геометрических характеристик и количества заходов винтовой канавки на прочессы теплообмена в диапазоне чисел Рейнольдса от 15000 до 65000. Анализ полученых результатов свидетельствует о том, что винтообразные трубы имеют в 1,5 - 2,6 раза выше интенсивность теплообтдачи в сравнении с гладкими трубами. Впервые определено влияние количества заходов винтообразной канавки на интенсивность теплоообмена внутри трубы. Результаты исследования могут быть использованы при разработке теплообменников типа «газ - газ»

Ключевые слова: винтообразная труба, равноразвитая поверхность, теплообмен, ефективность, интенсификация, вынужденная конвекция, численное моделирование. 